\title{
Novel Panel of Early Diagnostic Markers for Experimental Hepatocellular Carcinoma
}

\author{
Abdel-Hamid NM ${ }^{1, *}$, El-Moselhy MA ${ }^{2}$, Fawzy MA $^{1}$ \\ ${ }^{1}$ Biochemistry Departments, College of Pharmacy, Minia University, Egypt \\ ${ }^{2}$ Pharmacology Departments, College of Pharmacy, Minia University, Egypt
}

\begin{abstract}
Hepatocellular carcinoma (HCC) accounts for $80 \%$ to $90 \%$ of primary liver cancer and it is a major health problem worldwide, ranking the fifth most common cancer in the world. In the present study we aimed to explore new or highly pertinent rapid and sensitive markers for early diagnosis of hepatocellular malignant changes. Two groups of rats were used in this study, one served as control, the second as trichloroacetic acid (TCA) challenged group $(0.5 \mathrm{~g} / \mathrm{kg} / \mathrm{d}$ for 5 days, sacrificed after 4 weeks). The results showed that TCA group had a significant increase in blood alanine transaminase (ALT), aspartate transaminase (AST), alkaline phosphatase ( ALP), and acetyl CoA synthase (ACAS) activities, total bilirubin, triglycerides, total glycosaminoglycans (TGAGs), parallel with alpha-fetoprotein (AFP). On the other hand, it induced a significant reduction in serum total lipoprotein lipase (TLPL) activity. The histopathological investigations of hepatic tissue confirmed these neoplastic changes induced by TCA. The three parameters (TGAGs level, TLPL and ACAS activities) can be added as new markers for early diagnosis of hepatocellular carcinoma and elevation of the sensitivity and specificity of AFP.
\end{abstract}

Keywords Acyl Co A Synthase, AFP, Diagnosis, Liver Cancer, Sensitivity, Total Lipoprotein Lipase, Total Glycosaminoglycans

\section{Introduction}

Hepatocellular carcinoma (HCC) accounts for $80 \%$ to $90 \%$ of primary liver cancer. HCC is a major health problem worldwide, it is the fifth most common cancer in the world, and the third most common cause of cancer-related death[1]. The diagnosis of HCC is typically made by radiological liver imaging in combination with serum AFP. The later is a tumor marker that is elevated in $60 \%-70 \%$ of patients with HCC.

The specificity of AFP is very high when the levels are above $400 \mathrm{ng} / \mathrm{ml}$ [2]. In the few cases where diagnostic doubt persists, biopsy may be indicated. However, difficulty still exists in recognizing very small $(<1 \mathrm{~cm}) \mathrm{HCCs}[1]$.

The serum levels of AFP may also vary widely from one patient to another[3] and although the importance of AFP as diagnostic marker for HCC has been emphasized in clinical practice, there are very limited studies to look into the mechanism by which AFP levels among patients seem insensitive. HCC model in this study was induced by trichloroacetic acid (TCA) which is a common organic contaminant of drinking water formed as by-products during chlorine disinfection[4], Also TCA is a metabolite of

* Corresponding author:

nabilmohie@yahoo.com (Abdel-Hamid, NM)

Published online at http://journal.sapub.org/health

Copyright (C) 2012 Scientific \& Academic Publishing. All Rights Reserved trichloroethylene, a common industrial, commercial solvent and an environmental contaminant found in ground water at hazardous waste sites[5]. TCA affects liver as a primary target tissue for induction of cancer[6]. It was proposed that TCA generates free radicals during hepatic cytochrome P450- mediated dehalogenation reaction forming dichloroand monochloroacetic acids that mediate its carciogenicity[7]. In the present study, we aimed to explore new or highly related rapid and sensitive markers for early diagnosis of HCC, as most of known tumor markers appear at late stages of the disease. Acetyl CoA synthase, total lipoprotein lipase enzymes and glycosaminoglycans will be monitored along with AFP in a trial to raise its sensitivity and specificity in assessing HCC.

\section{Material and Methods}

\subsection{Chemicals and Drugs}

Trichloroacetic acid (TCA) was purchased from (El-Gomhorya Ph. Co. ARE) and rats were given TCA by gavages as $500 \mathrm{mg} / \mathrm{kg} /$ day for 5 days[8]. TCA was chosen because it has been reported to increase liver growth, cell proliferation, and lipid peroxidation in mice[7; 9-11]. All other chemicals used are of analytical grade obtained from Sigma (USA).

\subsection{Animals and Experimental Design}


Sixteen adult, male Wistar rats weighing 150-200 g, supplied from animal house of National Research Center (Dokki, Giza, Egypt) were used for experimental investigation in this study, according to the Ethics guidelines in the University committee of Experimental Animals. They were kept for 2 weeks to accommodate on laboratory conditions, under constant environmental and nutritional conditions with free access to food and water. Rats were classified into 2 groups (8 per each),group I: untreated normal healthy group and group 2: received single oral daily doses of TCA for five days.

The blood was withdrawn from the carotid vein by cutting with fine scissors after 4 weeks. The blood was collected by dripping into centrifuge tubes, sera were separated by centrifugation and samples were stored frozen at $-80{ }^{\circ} \mathrm{C}$. Liver tissue pieces were preserved in $10 \%$ formalin solution for histological study.

\subsection{Biochemical Investigations}

Serum ALT, AST, and ALP activities were determined according to method of $[12 ; 13]$ and[14] for ALP using commercial kits ( Biodiagnostic ,ARE).Total bilirubin (T Bil) was determined[15] and[16], using Randox Diagnostic kits (USA).Total glycosaminoglycans determination depends on the formation of soluble complex between TGAGs and Alcian blue $8 \mathrm{GX}$ dye[17]. Triglycerides(TG) were determined[18; 19], using Diamond kits (ARE) .TLPL activity was determined[20; 21] using Biostc kits (Italy). Serum AFP was determined[22-24] using ELISA Biocheck kits (USA) following the instructions of the manufacturer. Serum acetyl CoA synthase (ACAS) activity was determined based on the established pyrophosphate (PPi) detection system[25].

\subsection{Statistical Analysis}

The mean \pm SEM and the Student's $t$-test were carried out using SPSS and Graph Pad Prism programs. Significance was set at $\mathrm{P}<0.05$ level.

\section{Results}

\subsection{Biochemical Results}

A statistically significant increased activity in serum liver function enzymes, ALT, ALT and ALP, T Bil and TG in TCA-intoxicated rats $(\mathrm{P}<0.001)$, compared to healthy control values. Trichloroacetic acid (TCA) administration produced a significant decrease in serum TLP Activity at
$(\mathrm{P}<0.001)$ compared to healthy control untreated value. Serum TGAGs and AFP levels as well as, ACAS activity of TCA-intoxicated rats showed a significant increase compared to that of normal control group $(\mathrm{P}<0.001)$, as shown in Table 1:

AFP was positively correlated to TGAGs and acetyl CoA synthase enzyme but negatively correlated to TLPL activity (Fig 1):

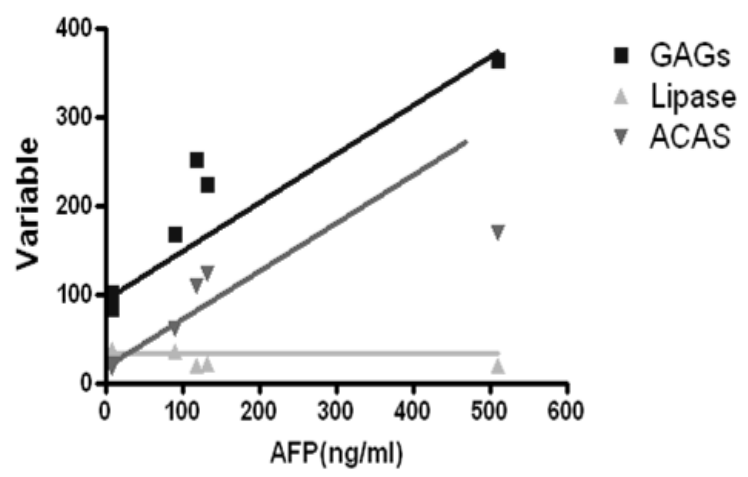

Figure 1. Pearson correlation coefficients of AFP versus TGAGs, TLPL and ACAS

Pearson correlation coefficients showed that changes in AFP exhibited positive correlation with TGAGs and acetyl CoA synthase enzyme but negative correlation with TLPL activity.

\subsection{Histopathological Results}

Liver histopathology after TCA administration showed loss of normal architecture with oval- or irregular-shaped hepatocytes. Many transformed liver cells foci were substantially enlarged, vesiculated, frequently binucleated and clearly distinguishable from the surrounding normal parenchyma. The nuclei were mostly pleomorphic, hyperchromatic compared to normal healthy group ( Fig 2, 3):

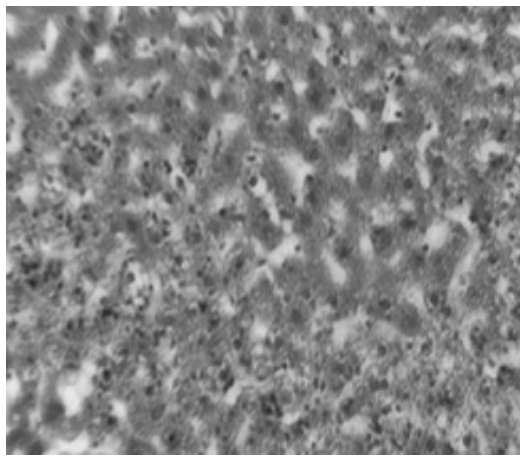

Figure 2. Photomicrograph of liver section in normal control animals

Table1. Shows the measured serum parameters in TCA intoxicated group (HCC group) given $500 \mathrm{mg} / \mathrm{kg} /$ day, orally for 5 days, compared to normal control

\begin{tabular}{|c|c|c|c|c|c|c|c|c|c|}
\hline Groups & $\begin{array}{c}\text { ALT } \\
(\mathrm{IU} / \mathrm{L})\end{array}$ & $\begin{array}{c}\text { AST } \\
(\mathrm{IU} / \mathrm{L})\end{array}$ & $\begin{array}{c}\text { ALP } \\
(\mathrm{IU} / \mathrm{L})\end{array}$ & $\begin{array}{c}\text { Bilirubin } \\
\text { (mg/dl) }\end{array}$ & $\begin{array}{c}\mathrm{TG} \\
(\mathrm{mg} / \mathrm{dl})\end{array}$ & $\begin{array}{l}\text { TLPL } \\
\text { (IU/L) }\end{array}$ & $\begin{array}{l}\text { TGAGs } \\
(\mu \mathrm{g} / \mathrm{ml})\end{array}$ & $\begin{array}{c}\text { AFP } \\
(\mathrm{ng} / \mathrm{ml})\end{array}$ & $\begin{array}{c}\text { FAS } \\
(\mathrm{mU} / \mathrm{ml})\end{array}$ \\
\hline Control & $12.375 \pm 2$ & $16 \pm 1.14$ & $20 \pm 1.4$ & $1.07 \pm 4.9$ & $67.7 \pm 2.7$ & $36.5 \pm 0.4$ & $83.8 \pm 6$ & $7 \pm 1.6$ & $17.6 \pm 1.5$ \\
\hline $\mathrm{TC}$ & $\begin{array}{c}62 \pm 3.56 \\
* * *\end{array}$ & $\begin{array}{r}55 \pm 6.3 \\
* * *\end{array}$ & $\begin{array}{c}00.3 \pm 7.0 \\
* * *\end{array}$ & $\begin{array}{r}3 \pm 0.36 \\
* * *\end{array}$ & $\begin{array}{r}14.1 \pm 4.0 \\
* * * *\end{array}$ & $\begin{array}{r}.8 \pm 0.9 \\
* * *\end{array}$ & $\begin{array}{r}364 \pm 12.1 \\
* * *\end{array}$ & $\begin{array}{c}10 \pm 69.4 \\
* * *\end{array}$ & $\begin{array}{r}170 \pm 5.5 \\
* * *\end{array}$ \\
\hline
\end{tabular}

Data are expressed as $\mathrm{X}^{-} \pm \mathrm{SEM}, \mathrm{N}=8$. ( ${ }^{* * *} \mathrm{P}<0.001$ : highly significant, compared to normal control) 


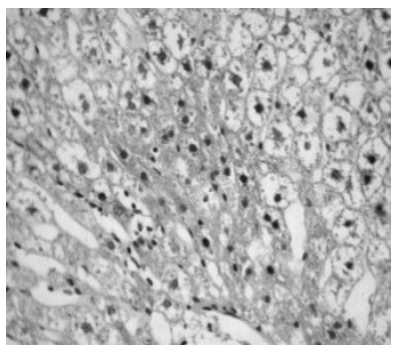

a

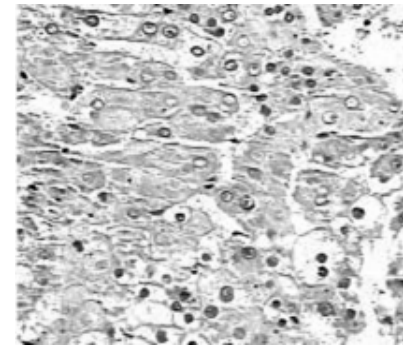

$\mathrm{b}$
Figure 3. a and b: Photomicrograph of liver section in TCA-treated rats

It revealed normal parenchymal cells with granulated cytoplasm and small uniform nuclei radially arranged around the central vein, normal sinusoids, and normal architecture.

\section{Discussion}

Although serum alpha-fetoprotein (AFP) level is still the most suitable tumor marker for the detection of early stage HCC, other HCC markers, such as des-gamma-carboxy prothrombin, alkaline phosphatase isoenzyme, and tissue polypeptide specific antigen, have been developed to improve the sensitivity, specificity, early detection, and prediction of prognosis; but the overall outcome seems to be unsatisfactory[26]. This is why HCC is a worldwide problem including Egypt. The need to explore new rapid and sensitive markers for early diagnosis of $\mathrm{HCC}$ is still a global concern.

Most of known tumor markers appear at late stages of the disease and almost don't contribute efficiently to disease management. In the present study, liver function tests performed for TCA-intoxicated rats showed an increase in the activity of serum ALT and AST. The elevation of both enzymes in serum is presumed to be due to leakage through damaged or necrotic cells[27]. Serum alkaline phosphatase (ALP) activity and total bilirubin level were significantly increased in TCA-intoxicated rats. This can be attributed to a mechanical obstruction of bile ducts and partial failure to excrete the enzyme and bilirubin through the relatively narrower bile passages[28] and such elevation in HCC was reported elsewhere[29].

Serum hyperlipidemia is a well documented phenomenon associated with hepatoma-bearing rats[30]. It may be explicated by the reduced activities of fat-splitting enzymes such as lecithin: cholesterol acetyltransferase (LCAT) and lipoprotein lipase (LPL) [31, 30].

In the current results, a significant increase of serum TG associated with a down regulation of TLPL, may indicate that the hydrolysis of the triacylglycerol component of circulating chylomicrons and very low density lipoproteins, providing non-esterified fatty acids and 2-monoacylglycerol for tissue utilization was possibly inhibited during hepatocarcinogenesis[32].

Glycosaminoglycans and proteoglycans are involved in the pathophysiology of most stages of cancer progression. The ability of cancer cells to invade into surrounding tissues involves changes in expression of cell-surface molecules and the expression of extracellular matrix(ECM)- degradative enzymes[33]. Changes in expression of these molecules reduce cell adhesion and promote cancer cell invasion. For a cancer to grow beyond a diameter of $2 \mathrm{~mm}$, primary tumors and metastases require nutrient support from the vascular system. Thus, angiogenesis is a crucial process that is targeted in cancer therapy. Apart from growth factors such as vascular endothelial growth factors, fibroblast growth factors, and angiopoietins, glycosaminoglycans and proteoglycans are involved in angiogenesis[34]. In our work study, serum total glycosaminoglycans level of TCA-intoxicated rats showed a significant increase. Significant increase in GAGs have been demonstrated in many kinds of human cancers, viz, laryngeal[35], rectal[36], colon[37], gastric[38] and pancreatic[39].

Alpha-fetoprotein is a well-known tumor marker, useful not only for diagnosis, but also prediction of invasiveness and recurrence of HCC. Patients with high AFP levels at diagnosis are deemed to have greater tumor size, bilobar involvement, massive or diffuse types and portal vein thrombosis. AFP is also a significant prognostic factor for recurrent HCC[40]. Here, serum AFP level of TCA-intoxicated rats showed a significant increase proving the occurrence of HCC in intoxicated rats [29; 41].

There is a strong association between increased ACAS activities and the presence of other unfavorable prognostic indicators in primary breast, prostate, colorectal and ovarian cancers[42]. In our work, the significant up regulation of serum ACAS activity of TCA-intoxicated rats can be attributed to cellular proliferation and fatty acid synthesis, because fatty acid synthesis has been observed to be a prerequisite for cells to enter into proliferative phase in several systems[43]. This result is in agreement with findings of [42] in which ACAS activity was increased in breast and colorectal cancer.

These biochemical derangements were confirmed by histological findings, that clearly showed that TCA treatment, led to all signs of malignant transformation and carcinogenesis with the formation of neoplastic nodules and ultimately HCC[44].

Conclusion: The present study produced convincing evidence that combining serum TGAGs and TG levels, ACoAS and TLPL enzyme activities to AFP can be considered as new promising panel for early diagnosis of HCC. Taken together after experimental induction of $\mathrm{HCC}$, it can be recommended to use this panel in patients having risk factors for HCC. Mostly, these results may assume more decisive and sensitive tool for HCC early assessment and follow-up.

\section{REFERENCES}

[1] W.Y. Lau, Management of hepatocellular carcinoma. J R Coll Surg Edinb 47 (2002) 389-99.

[2] A.S. Befeler, and A.M. Di Bisceglie, Hepatocellular carcinoma: diagnosis and treatment. Gastroenterology 122 
(2002) 1609-19.

[3] P.J. Johnson, The role of serum alpha-fetoprotein estimation in the diagnosis and management of hepatocellular carcinoma. Clin Liver Dis 5 (2001) 145-59.

[4] W.J. Chen, and C.P. Weisel, Concentration Changes of Halogenated disinfection by-Products in a Drinking Water Distribution System. J. Am. Water Works Assoc 90 (1998) 151-163.

[5] Iarc, International Agency for Research on Cancer,Trichloroethylene, Iarc Monograph on the Evaluation of the Carcinogenic Risk of Chemicals to Human. IARC, Lyon, France (1995) 75-158.

[6] H.J. Clewell, and M.E. Andersen, Applying mode-of-action and pharmacokinetic considerations in contemporary cancer risk assessments: an example with trichloroethylene. Crit Rev Toxicol 34 (2004) 385-445.

[7] J.L. Larson, and R.J. Bull, Metabolism and lipoperoxidative activity of trichloroacetate and dichloroacetate in rats and mice. Toxicol Appl Pharmacol 115 (1992) 268-77.

[8] L. Tao, S. Yang, M. Xie, P.M. Kramer, and M.A. Pereira, Effect of trichloroethylene and its metabolites, dichloroacetic acid and trichloroacetic acid, on the methylation and expression of c-Jun and c-Myc protooncogenes in mouse liver: prevention by methionine. Toxicol Sci 54 (2000) 399-407.

[9] S.R. Channel, J.R. Latendresse, J.K. Kidney, J.H. Grabau, J.W. Lane, L. Steel-Goodwin, and M.C. Gothaus, A subchronic exposure to trichloroethylene causes lipid peroxidation and hepatocellular proliferation in male $\mathrm{B} 6 \mathrm{C} 3 \mathrm{~F} 1$ mouse liver. Toxicol Sci 43 (1998) 145-54.

[10] C. Dees, and C. Travis, Trichloroacetate stimulation of liver DNA synthesis in male and female mice. Toxicol Lett 70 (1994) 343-55.

[11] J.A. Styles, I. Wyatt, and C. Coutts, Trichloroacetic acid: studies on uptake and effects on hepatic DNA and liver growth in mouse. Carcinogenesis 12 (1991) 1715-9.

[12] S. Rietman, and S. Frankle, A Colorimetric Method for Determination of Serum Glutamic Oxaloacetic and Glutamic Pyruvic Transaminases. Am. J. Clin. Path 28 (1957).

[13] N. Gond, and S. Khadabadi, Hepatoprotective activity of Ficus carica leaf extract on rifampicin-induced hepatic damage in rats. Indian J Pharm Sci 70 (2008) 364-6.

[14] A. Belfield, and D.M. Goldberg, Revised assay for serum phenyl phosphatase activity using 4-amino-antipyrine. Enzyme 12 (1971) 561-73.

[15] L. Jendrassik, and P. Grof, Biochem. J 297 (1938) 81.

[16] P.J. Bosma, J.R. Chowdhury, C. Bakker, S. Gantla, A. de Boer, B.A. Oostra, D. Lindhout, G.N. Tytgat, P.L. Jansen, R.P. Oude Elferink, and et al., The genetic basis of the reduced expression of bilirubin UDP-glucuronosyltransferase 1 in Gilbert's syndrome. N Engl J Med 333 (1995) 1171-5.

[17] E.W. Gold, A simple spectrophotometric method for estimating glycosaminoglycan concentrations. Anal Biochem 99 (1979) 183-8.

[18] N.J. Jacobs, and P.J. Vandemark, The purification and properties of the alpha-glycerophosphate-oxidizing enzyme of Streptococcus faecalis 10C1. Arch Biochem Biophys 88 (1960) 250-5.

[19] P. Trinder, Enzymatic Calorimetric Test Clin. Biochem. J 6 (1969) 24-27.

[20] N.W. Tietz, Textbook of Clinical Chemistry. W.B. Saunders CO Philadelphia (1999).

[21] D.S. Young, Effect of Drugs on Clinical Lab Test. 5th Ed. AACC press (2000).

[22] G.I. Abelev, Alpha-fetoprotein as a marker of embryo-specific differentiations in normal and tumor tissues. Transplant Rev 20 (1974) 3-37.

[23] D.W. Chan, and Y.C. Miao, Affinity chromatographic separation of alpha-fetoprotein variants: development of a mini-column procedure, and application to cancer patients. Clin Chem 32 (1986) 2143-6.

[24] M. Uotila, E. Ruoslahti, and E. Engvall, Two-site sandwich enzyme immunoassay with monoclonal antibodies to human alpha-fetoprotein. J Immunol Methods 42 (1981) 11-5.

[25] Y. Kuang, N. Salem, F. Wang, S.J. Schomisch, V. Chandramouli, and Z. Lee, A colorimetric assay method to measure acetyl-CoA synthetase activity: application to woodchuck model of hepatitis virus-induced hepatocellular carcinoma. J Biochem Biophys Methods 70 (2007) 649-55.

[26] D.F. Yao, Z.Z. Dong, and M. Yao, Specific molecular markers in hepatocellular carcinoma. Hepatobiliary Pancreat Dis Int 6 (2007) 241-7.

[27] M.C. Kew, Serum aminotransferase concentration as evidence of hepatocellular damage. Lancet 355 (2000) 591-2.

[28] D.V. Gopal, and H.R. Rosen, Abnormal findings on liver function tests. Interpreting results to narrow the diagnosis and establish a prognosis. Postgrad Med 107 (2000) 100-2, 105-9, 113-4.

[29] W. Yeo, F.K. Mo, J. Koh, A.T. Chan, T. Leung, P. Hui, L. Chan, A. Tang, J.J. Lee, T.S. Mok, P.B. Lai, P.J. Johnson, and B. Zee, Quality of life is predictive of survival in patients with unresectable hepatocellular carcinoma. Ann Oncol 17 (2006) 1083-9.

[30] G. Zhang, Y. Miura, and K. Yagasaki, Effects of dietary powdered green tea and theanine on tumor growth and endogenous hyperlipidemia in hepatoma-bearing rats. Biosci Biotechnol Biochem 66 (2002) 711-6.

[31] G. Muralikrishnan, V. Amalan Stanley, and K. Sadasivan Pillai, Dual role of vitamin C on lipid profile and combined application of cyclophosphamide, methotrexate and 5 -fluorouracil treatment in fibrosarcoma-bearing rats. Cancer Lett 169 (2001) 115-20.

[32] R.W. Clark, and R.C. Crain, Characterization of Alterations in Plasma Lipoprotein Lipid and Apoprotein Profiles Accompanying Hepatoma-Induced Hyperlipidemia in Rats. Cancer Res 46 (1986) 1894-1903.

[33] N.M. Abdel-Hamid, Premalignant variations in extracellular matrix composition in chemically induced hepatocellular carcinoma in rats. J Membr Biol 230 (2009) 155-62.

[34] G.W. Yip, M. Smollich, and M. Gotte, Therapeutic value of glycosaminoglycans in cancer. Mol Cancer Ther 5 (2006) 
2139-48.

[35] S.S. Skandalis, M. Stylianou, D.H. Vynios, N. Papageorgakopoulou, and D.A. Theocharis, The structural and compositional changes of glycosaminoglycans are closely associated with tissue type in human laryngeal cancer. Biochimie 89 (2007) 1573-80.

[36] M.E. Tsara, A.D. Theocharis, and D.A. Theocharis, Compositional and structural alterations of proteoglycans in human rectum carcinoma with special reference to versican and decorin. Anticancer Res 22 (2002) 2893-8.

[37] A.D. Theocharis, Human colon adenocarcinoma is associated with specific post-translational modifications of versican and decorin. Biochim Biophys Acta 1588 (2002) 165-72.

[38] A.D. Theocharis, D.H. Vynios, N. Papageorgakopoulou, S.S. Skandalis, and D.A. Theocharis, Altered content composition and structure of glycosaminoglycans and proteoglycans in gastric carcinoma. Int J Biochem Cell Biol 35 (2003) 376-90.

[39] S.S. Skandalis, D. Kletsas, D. Kyriakopoulou, M. Stavropoulos, and D.A. Theocharis, The greatly increased amounts of accumulated versican and decorin with specific post-translational modifications may be closely associated with the malignant phenotype of pancreatic cancer. Biochim Biophys Acta 1760 (2006) 1217-25.
[40] L.X. Qin, and Z.Y. Tang, Metastasis and Recurrence after Surgical Resection of Hepatocellular Recent Progress in Clinical and Related Basic Aspects Carcinoma. Current Cancer Therapy Reviews 1 (2005) 71-80.

[41] L.P. Borges, V.C. Borges, A.V. Moro, C.W. Nogueira, J.B. Rocha, and G. Zeni, Protective effect of diphenyl diselenide on acute liver damage induced by 2-nitropropane in rats. Toxicology 210 (2005) 1-8.

[42] Y. Wang, F.P. Kuhajda, J.N. Li, E.S. Pizer, W.F. Han, L.J. Sokoll, and D.W. Chan, Fatty acid synthase (FAS) expression in human breast cancer cell culture supernatants and in breast cancer patients. Cancer Lett 167 (2001) 99-104.

[43] N. Yahagi, H. Shimano, K. Hasegawa, K. Ohashi, T. Matsuzaka, Y. Najima, M. Sekiya, S. Tomita, H. Okazaki, Y. Tamura, Y. Iizuka, K. Ohashi, R. Nagai, S. Ishibashi, T. Kadowaki, M. Makuuchi, S. Ohnishi, J. Osuga, and N. Yamada, Co-ordinate activation of lipogenic enzymes in hepatocellular carcinoma. Eur J Cancer 41 (2005) 1316-22.

[44] C. Peraino, E.F. Staffeldt, and V.A. Ludeman, Early appearance of histochemically altered hepatocyte foci and liver tumors in female rats treated with carcinogens one day after birth. Carcinogenesis 2 (1981) 463-5. 